\title{
Pre-service Science Teachers' Construction and Interpretation of Graphs*
}

\author{
N. Remziye Ergül \\ Education Faculty, Uludağ University, Turkey
}

Copyright $(\mathrm{C} 2018$ by authors, all rights reserved. Authors agree that this article remains permanently open access under the terms of the Creative Commons Attribution License 4.0 International License

\begin{abstract}
Data and graphic analysis and interpretation are important parts of science process skills and science curriculum. So it refers to visual display of data using relevant graphical representations. One of the tools used in science courses is graphics for explain the relationship among each of the concepts and therefore it is important to know data analysis, graph construction and interpretation. This study investigates pre-service science teachers' construction and interpretations of graphs in two different domains: mathematics and physics. Qualitative research methods were used and therefore a purposive sample of 11 pre-service science teachers is engaged in think-aloud interviews while completing the questionnaire that includes eleven open-ended questions, designed by researcher at four different categories. These categories are: recognition as a mathematical graph, Interpretation of the graph, to draw graphs for a given problem and to create a problem on a given graphic. In addition, the pre-service science teachers were asked in which questions they experienced difficulties. Content analysis method was used for data analysis. Results showed that pre-service science teachers do not have enough success in interpreting given graph, drawing graph for a given problem and identifying variables in a given scientific problem.
\end{abstract}

Keywords Construction of Graphs, Interpretations of Graphs, Pre-service Science Techers, Physics

\section{Introduction}

Besides knowing about concepts of science and mathematics, students' acquiring the attitude of thinking and behaving like a science person occupies an important place among the goals of education as well. Skills of making observations, collecting, organizing and interpreting data are necessary skills in this context. One of the ways of organizing and making sense of statistical data is drawing graphs.
According to Glazer [1], together with data organization and interpretation depending on gradually growing importance of scientific research skills, graph interpretation competencies have become an important factor in terms of understanding today's world and scientific literacy and graph interpretation competencies, for example, are affected by many factors such as features of graphs, content of the graph and knowledge structure of the interpreter. In order to cope with skills such as possessing critical thinking skills emphasized as the $21 \mathrm{st}$ century requirements, applying knowledge to new situations, analyzing information, comprehending new ideas, possessing communication and cooperation skills, problem solving, using technology and making decisions, students need more than working on main subjects $(21 \mathrm{st}$ century workforce commission). Besides this, in the $21 \mathrm{st}$ century, different skills such as the ability to work with data, that is to say, drawing conclusions from data in hand, finding tendencies, using and evaluating data with the aim of interpreting data and supporting assumptions are important as well. Together with the increasingly growing information and technology, graphs and visual data presentations in tables have turned into daily life activities and increased information age literacy in many areas and.

Graph identification, graph drawing and graph interpretation are a whole and one of the fundamental tools of the courses of mathematics and science. A graph includes many pieces of information at the same time. Lienhard et al. [2], stated that a graph has two dimensions, namely interpretation and drawing, and these require skills of classification, prediction, scaling and transformation. Bayazit [3] states that graphs have an interdisciplinary and even supra-disciplinary function. When the relationship between physics and mathematics is taken into consideration, students' seeing and using this relationship is very important in terms of understanding physics. For example, Woolnough [4] stated that students cannot see relationships between physics, mathematics and real world, draw borders between them and themselves and develop a thinking system like this: For physics, they say it includes special laws and many problems and related equations 
which require solving; some experiments are made and graphs can be drawn to explain the result of an experiment; for mathematics, they say it includes many rules stated in $x$ and $y$, constants such as $a, b$ and $c$ and graphs characterized with $\mathrm{x}$ and $\mathrm{y}$. In physics lessons, one of the tools used to state relationships between many physics concepts is graphs. For this reason, students' understanding and interpreting relationships between physics concepts correctly directly depends on their understanding and interpreting graphs well. (Demirci and Uyanık [5])

When studies on drawing and interpretation of graphs are examined, it is observed that there are short-comings at every level. For example, Demirci and Uyanı [5] investigated the relationships between the 10th grade students' skills of drawing and understanding graphs and their skills of interpreting kinematic graphs and found a significant relationship. Işık at al. [6] found that the preservice classroom teachers had various difficulties in making up stories for line graphs related to daily life situations. Wemyss and Kampen [7] investigated the university first year students' skills of interpreting numerical linear distance - time graphs and found that they were incompetent in interpreting graph slopes. Foster [8], determined that the students failed to decide on the best line when drawing line graphs, read scales correctly, pay attention to scaling when drawing and confused height/slope and space-point. Bowen and Roth [9] investigated the primary and secondary school science preservice teachers' data and graph interpretation competencies and, as a result, determined that the preservice teachers needed to do much more practices and acquire experience. In a study with high school students, Planinic at al. [10] tried to reveal differences by taking the understanding of the slope of line graphs in hand within the scope of physics (kinematics) and mathematics and determined that the students had problems related to physics subjects. Şahinkaya and Aladağ [11] investigated the preservice classroom teachers' general opinions about graphs and obtained the results that although they had some misconceptions, they managed to define graphs; they believed that teaching of graphs would be useful; they had insufficient knowledge of general graph types. Taşar, Ingeç and Güneş [12] investigated the basic elements of the skill of drawing and understanding graphs to measure this skill and determined nine elements. Within this framework, they developed a multiple-choice test, but they emphasized the necessity of including open-ended questions in the measurement by putting forward the idea that the test which they developed was insufficient in this form.

\subsection{Purpose of the Study}

The purpose of the study is to investigate preservice science teachers' graph construction and interpretation skills within the scope of the knowledge of physics and mathematics. For this purpose, four categories were determined. These are:

1. Knowledge of identifying graphs mathematically

2. Interpreting graphs

3. Determining the graph to be drawn for a given problem and drawing correctly

4. Stating a suitable problem for a given graph.

\subsection{The Study Group}

Within the scope of the study were included 11 volunteer students enrolled in the fourth year of the Science Teaching department.

\section{Method}

With the aim of investigating the preservice science teachers' skills of graph construction, drawing and interpretation by using the knowledge of physics and mathematics, 12 questions belonging to the above-mentioned four categories were prepared. The questions were organized in worksheets and given to the students under the supervision of the researcher. The study was carried out in two-hour-a-week sessions for two weeks. With the aim of measuring the knowledge of identifying a graph mathematically and determining which relation and function it is suitable for, ten different graphs were given in the first question. The students were given a graph drawn in accordance with the linear equation, three parabolas, two graphs representing exponential function, again two graphs representing logarithmic function and a graph representing a polynomial of the third degree and asked to explain which relation or function, these graphs represented mathematically and write their equations. With the aim of measuring graph interpretation skills, 4 questions were asked. In this context, with the aim of measuring the knowledge of determining variables, a simple experiment was given and they were asked to determine the variables belonging to the experiment and show them on the related graph; some graph examples were given and they were asked to determine these graphs in bar graph, histogram and line graph; a bar graph was given and they were asked to interpret this graph; a math problem and various graphs were given and they were asked to determine the graph belonging to this problem; a graph belonging to a physics problem and they were asked to obtain the result related to the problem by benefiting from the graph. In line with the third problem, three questions were asked. For example, a problem related to daily life and they were asked to draw a graph belonging to the problem; a problem including an exponential function was given and they were asked to obtain data by using this function, draw a graph by using this data and interpret the obtained graph; a second-degree equation with one unknown was given and they were asked to calculate the unknown value with the help of a graph. In line with the fourth question, 2 questions were asked. For 
example, some graphs were given and they were asked to write an appropriate scenario telling the kind of an event which these graphs represent. Finally, they were asked to write about the question or questions which they found the most difficult. In addition to this, observations were made and one-to-one interviews were held with the students during the study. For example, possible reasons why they could not solve a question, or had difficulty in solving it were discussed. In the end of the study, content analysis was applied to the obtained data. We can try to describe the data and reveal truths which might be hidden in data through the content analysis. (Yıldırım, A., Şimşek, H. [13])

\section{Findings}

The evaluation results of the worksheets including eleven questions were summarized in Table 1 . In the table, the students were shown through enumeration from 1 to 11 .

According to Table 1, the first question was grouped as a, b, c, d, e, f within the scope of the knowledge of identifying the graph mathematically. According to this, a represents the linear graph, b represents the parabola, c represents the graph belonging to the equation of $\mathrm{y}=\mathrm{ax}^{3}, \mathrm{~d}$ represents the graph belonging to the graph of $x=y^{2}$, e represents the exponential function and f represents the graphs belonging to the logarithmic function. In the table, the letters under each student represent the graphs which students identified. As it is seen from the table, all the students, except for one, identified the graphs belonging to the line and parabola. Only one student identified the graph belonging to the equation of $y=\mathrm{ax}^{3}$. Four students identified the graph belonging to the equation of $x=y^{2}$, two students identified the graph belonging to the exponential function and five students identified the graph belonging to the logarithmic function. In the second question, they were asked to determine variables belonging to a given physics problem: "You have obtained the some data making an experiment measuring the strength of a stretch of a pack tire and write these variables on their places in the given graph.?" In Table 1, the symbol ' $C$ ' represents the correct writing of the variables, the symbol ' $\mathrm{W}$ ' represents the incorrect writing of the variables, the symbol ' + ' represents the correct showing of the variables on the graph and the symbol '-' represents the incorrect showing of the variables on the graph. According to this, one student answered the question completely; although three students answered the variables correctly, they showed them on the graph incorrectly; two students identified the variables incorrectly but showed on the graph correctly; five students answered both of them incorrectly.

Table 1. Distribution of the students' answers according to the questions

\begin{tabular}{|c|c|c|c|c|c|c|c|c|c|c|c|}
\hline \multirow{2}{*}{ Question Number } & \multicolumn{11}{|c|}{ Student Number } \\
\hline & 1 & 2 & 3 & 4 & 5 & 6 & 7 & 8 & 9 & 10 & 11 \\
\hline 1 & $\mathrm{a}, \mathrm{b}$ & $\mathrm{a}, \mathrm{b}, \mathrm{c}, \mathrm{d}$ & $\mathrm{a}, \mathrm{b}, \mathrm{d}, \mathrm{e}, \mathrm{f}$ & $\mathrm{a}, \mathrm{b}, \mathrm{d}, \mathrm{e}, \mathrm{f}$ & $\mathrm{a}, \mathrm{b}, \mathrm{f}$ & $\mathrm{a}, \mathrm{b}$ & $\mathrm{a}, \mathrm{b}, \mathrm{d}, \mathrm{f}$ & $\mathrm{a}, \mathrm{b}$ & $\mathrm{a}, \mathrm{b}$ & $a, b, f$ & - \\
\hline 2 & $\mathrm{C},-$ & $\mathrm{C},-$ & $\mathrm{W},+$ & $\mathrm{Y},+$ & $\mathrm{C},+$ & $\mathrm{W},-$ & $\mathrm{W},-$ & $\mathrm{C},-$ & $\mathrm{W},-$ & $\mathrm{W},-$ & W,- \\
\hline 3 & + & + & + & + & + & + & + & + & - & + & + \\
\hline 4 & + & + & - & - & + & - & + & + & + & + & - \\
\hline 5 & + & + & + & + & + & + & + & + & - & + & - \\
\hline 6 & + & + & - & - & + & - & - & - & - & + & - \\
\hline 7 & + & + & + & + & - & - & - & - & - & - & - \\
\hline 8 & + & - & - & + & - & + & - & + & - & - & - \\
\hline 9 & - & - & $*$ & $*$ & - & $*$ & $*$ & - & - & - & - \\
\hline 10 & + & - & - & - & + & - & + & + & - & + & - \\
\hline 11 & - & - & - & - & - & - & - & - & - & - & - \\
\hline
\end{tabular}


In the third question, the students were asked to show the given graphs as bar graphs, histograms and line graphs. All the students, except for one, answered this question correctly. In the fourth question, the students were given a bar graph and asked to interpret this bar graph. According to this, four students gave incorrect answers, but all the remaining students gave correct answers. Although most of the students were knowledgeable of the bar graph, they failed to interpret it. In the fifth question, a physics problem was given and asked to find the graph which was appropriate for the problem. Except for two students, the others gave correct answers. In the sixth question, the students were asked to draw the graph belonging to the given problem. According to this, it was observed that four students managed to give correct answers. In the seventh question, the students were asked to draw a conclusion from a given velocity - time graph. In this question, four students were successful. In the eighth question, the students were asked to write an appropriate scenario for the given graph. In this question, too, four students were successful. In the ninth question, a problem including an asked to draw the graph of this function and find the result. None of the students managed to answer this question completely. Some students made the calculation but failed to draw the graph. The symbol $(*)$ represents these students. In the tenth question (taken from PISA 2016 exam), some conditions belonging to an event were given and the students were asked to find the graph meeting these conditions. It was observed that five students managed to answer. In the eleventh question, the equation of $y=A 2^{x}$ was given and the students were asked to find the value of the number ' $A$ ' with the help of a graph. In this question, it was observed that the students were not successful.

Finally, the students were asked to explain which questions and why they had difficulty in answering. The obtained answers were shown in Table 2.

In Table 2, which student had difficulty in answering which questions was expressed in question numbers? Here, the most difficult question was the ninth question with 8 students. . It was followed by the first question with 6 students. After these, the eleventh question came with 4 students; then, the seventh question came with 2 students; exponential function was given and the students were

finally, the third and sixth questions came with one student. For example, the ninth question was stated as: "The population of a city was given with the formula (Caferov, V. [14]) of approximately

$$
\mathrm{N}(\mathrm{t})=100000 . \mathrm{e}^{0,04(\mathrm{t}-1980)} \text {. }
$$

Here, the variable ' $t$ ' indicates 'year'. Show the results on a graph by calculating the expected values of the population for the years 2020, 2030 and 2050. What kind of a graph did you obtain?" As a result of the calculations, the students were expected to draw a bar graph by finding discrete values. Most of the students, as it was in the third question, knew of the structure of a bar graph. Here it can be concluded that they had difficulty in making calculations with exponential functions. In fact, in the interviews held, too, the students made explanations in this way. In conclusion, lack of mathematical knowledge is prominent. The first question is, mathematically, a question belonging to the knowledge of identifying a graph. As it is seen in Table 1, most of the students failed to identify a graph in the structure of a third degree polynomial. Only one student identified the graph. Although our students received the related mathematical lessons in high school years and during their university education, the obtained result is meaningful. Although the eleventh question is a simple graph drawing question, 4 students stated having difficulty in solving it, but actually none of them managed to solve it.

If we look in some interviews held with the students in relation to the questions, we see that they made similar explanations:

Student numbered 1: "I had difficulty in solving the first
question because I failed to remember related
background information".
Student numbered 5: "I had difficulty in solving the first
and the ninth questions because I paid no attention to the
graphs".
Student numbered 6: "I have never seen a graph like the
one in the eighth question; in fact, I do not know to draw
a graph well as it was in the ninth question".
Student numbered 8: "I cannot manage to interpret
graphs given in the form of an equation or whose
equations are wanted, for I'm not accustomed to".

Table 2. Distribution of the questions which the students had difficulty in answering

\begin{tabular}{|c|c|c|c|c|c|c|c|c|c|c|c|}
\hline & \multicolumn{10}{|c|}{ Student Number } \\
\cline { 2 - 13 } & 1 & 2 & 3 & 4 & 5 & 6 & 7 & 8 & 9 & 11 \\
\hline Question Number & 1 & 9 & 9,11 & 2,7 & 1,9 & 1,9 & 1,9 & 1,9 & $3,6,7,11$ & 9,11 & $1,9,11$ \\
\hline
\end{tabular}




\section{Interpretation and Conclusions}

When the obtained data is evaluated in general, it is observed that the students were unsuccessful in graph identification and interpretation. Among the reasons can be shown the forgetting of mathematical knowledge and relationally the inability to use this knowledge in physics lessons and analyze the mathematical structure of physical formulas. Woolnough [4] stated that the students had difficulty in transferring their mathematical knowledge into physics. Boote [15] investigated the line graph interpretation skills of the 13-14-year-old students having received mathematics and science education and factors affecting these interpretations and reached the result that mathematical knowledge is important in the interpretation of graphs and emphasized the result that mathematical methods used by students cannot be observed through the multiple-choice type evaluations. Physical formulas are each a mathematical equation. For example, although students stated that the equation of $y=a x+b$ is a linear equation, they cannot see that the physical formulas of $\mathrm{F}=\mathrm{ma}$ or $\mathrm{v}=\mathrm{v}_{0}+\mathrm{at}$ are in the structure of a linear equation. Or when we take the movement with constant momentum taught in relation to kinematics into consideration, the location-time relationship is expressed with the equation of $\mathrm{x}=\mathrm{x}_{0}+\mathrm{v}_{0} \mathrm{t}+1 / 2 \mathrm{at}^{2}$. This equation corresponds mathematically to a second degree equation and expressed as a parabola. That is to say, when we take the location-time graph belonging to a movement in hand, this should be a parabola. However, since students cannot interpret an equation mathematically, many students become unsuccessful when they are asked to draw the location-time graph. Or students state that they can draw a graph since they remember how to draw it because of seeing it in the book or the teacher's drawing it before. One of the results obtained by Lienhard et al. [2] was that the students saw the graph as a picture. For example, they interpreted the location-time graphs as a road or travel map. In this respect, when they write an equation explaining a physics principle, physics teachers should not also mention the physical interpretation of the equation but they also mention the mathematical structure of it. For when a mathematical structure is clear, relationships between physical variables in an equation can be interpreted more clearly and the relationship between the variables can be transferred to the graph more understandably. One of the results reached by Nixon at al. [16] in a laboratory study which they made with physics undergraduate students was that the students were successful in drawing graphs, but they did not generally take into account the physics underlying the graphs. The results of the study made by Alacacı at al.[17] with preservice elementary school teachers support our results, too. Moreover, according to this study, too, the students had little or no knowledge of scatterplots; the results also pointed to the interdependence of graph knowledge with general mathematical knowledge.
Moreover, another result of the study was that the students had insufficient knowledge and skill of drawing graphs. As a reason for this situation, the students explained that they did not do any experiments in high school years; for this reason, they did not draw any graphs and do not attach much importance to it during university years. The results of the study carried out by Bayazit [3] with the students enrolled in the Science and Classroom Teaching departments are in this direction. It was found in the study that although the students knew the relationship between the area and the edge of the square, they could draw the graph indicating this relationship only at a rate of $40 \%$. Planinic at al. [18], in a study which they carried out with preservice physics and mathematics teachers, dealt with the subject of kinematics and determined that the students preferred to solve the kinematic problems with the help of formulas rather than using graphs. Similarly, in a study with physics and mathematics students, Ivanjek at al. [19] reached the result that the physics students preferred to use formulas.

In conclusion, as a way of increasing success in physics lessons, students should be explained the mathematical structure of physics equations and they should be made to see this relationship. For, the importance of this relationship is clear in the essence of graph drawing and interpretation.

\section{REFERENCES}

[1] Glazer, N. (2011). Challenges with graph interpretation: a review of literature. Studies in Science Education 47(2), $183-210$.

[2] Lienhardt, G., Zaslavsky, O., \& Stein, M. K. (1990). Functions, graphs, and graphing: Tasks, learning, and teaching. Review of Educational Research, 60(1), 1-64.

[3] Bayazıt, İ. (2011). "Öğretmen Adaylarının Grafikler Konusundaki Bilgi Düzeyleri.” Gaziantep Üniversitesi Sosyal Bilimler Dergisi, 10 (4): 1325 -1346

[4] Woolnough, J. (2000). How do students learn to apply their mathematical knowledge to interpret graphs in physics? Research in Science Education, 30 (3), 259-267.

[5] Demirci, N., \& Uyanık, F., (2009). Onuncu Sinıf Öğrencilerinin Grafik Anlama ve Yorumlamaları İle Kinematik Başarıları Arasındaki İlişki. Necatibey Faculty of Education Electronic Journal of Science and Mathematics Education, 3(2), 22-51.

[6] Iş̧1k, C., Kar, T., İpek, A. S., \& Işık, A. (2012). Difficulties encountered by pre-service classroom teachers in constructing stories about line graphs. International Online Journal of Educational Sciences, 4(3), 644-658.

[7] Wemyss, T., \& Kampen, P. V. (2013). Categorization of First-Year University Students' Interpretations of Numerical Linear Distance-Time Graphs. Physical Review Special Topics - Physics Education Research, 9(1), 107-123. 
[8] Foster, P.A. (2004). Graphing in physics: Processes and sources of error in tertiary entrance examinations in Western Australia. Research in science Education, 34, 239-265.

[9] Bowen, G.M. \& Roth, W.-M. (2005). Data and graph interpretation practices among preservice science teachers. Journal of Research in Science Teaching. 42, 1063-1088.

[10] Planinic, M., Milin-Sipus, Z., Katic, H., Susac, A., \& Ivanjek, L. (2012). Comparison of student understanding of line graph slope in physics and mathematics, Int. J. Sci. Math. Educ. 10: 1393-1414.

[11] Sahinkaya, N., Aladağ, E. (2013). The views of pre-service class teachers on graphics. Adryaman Sosyal Bilimler Enstitüsü Dergisi, 6 (15) pp. 309-328.

[12] Taşar, M.F., İngeç, Ş. K., \& Güneş, P.Ü. (2002). Grafik çizme ve anlama becerisinin saptanması. V. Ulusal Fen Bilimleri ve Matematik Eğitimi Kongresi, ODTÜ, Ankara.

[13] Yıldırım, A., Şimşek, H. (2011). Sosyal Bilimlerde Nitel Araştırma Yöntemleri. (8. baskı). Ankara: Seçkin Yayıncilik.

[14] Caferov, V. Anadolu Üniversitesi Açık Öğretim Fakültesi yaymlar1. Retrieved January 12, 2016, from
https://tr.scribd.com/document/257121058/Unite-5-USTEL -VE-LOGARITTMIK-FONKSYONLAR

[15] Boote, S.K. (2014). Assessing and understanding line graph interpretations using a scoring rubric of organized cited factors. Journal of Science Teacher Education, 25(3), 333-354.

[16] Nixon, R. S., Godfrey, T. J., Mayhew, N. T., \& Wiegert, C. C. (2016). Undergraduate student construction and interpretation of graphs in physics lab activities. Physical Review Physics Education Research, 12(1), 010104.

[17] Alacaci,C., Lewis S., O’Brien E.G. \& Jiang Z. (2011). Pre-service elementary teachers' understanding of graphs. Eurasia Journal of mathematics, Science and Technology Education. 7 (1), 3-14.

[18] Planinic, M., Ivanjek, L., Susac, A., and Sipus, Z.M. (2013). Comparison of university students' understanding of graphs in different contexts, Physical Review Special Topics- Phys. Educ. Res. 9, 020103.

[19] Ivanjek,L., Susac, A., Planinic, M., Andrasevic, A., and Sipus, Z.M. (2016). Student reasoning about graphs in different contexts. Phys. Rev. Phys. Educ. Res., Vol. 12, Iss. 1.

*This study was presented as an oral presentation of the 4th International Symposium on New Issues in Teacher Education, held in Savonlinna, Finland on 30 August-1 September 2016. 